REVIEW

\title{
Cocaine and the heart
}

\author{
M Egred, G K Davis
}

Postgrad Med J 2005;81:568-571. doi: 10.1136/pgmj.2004.028571

Cocaine is the second commonest illicit drug used and the most frequent cause of drug related deaths. Its use is associated with both acute and chronic complications that may involve any system, the most common being the cardiovascular system. Cocaine misuse has a major effect in young adult drug users with resulting loss of productivity and undue morbidity with cocaine related cardiac and cerebrovascular effects. Many cocaine users have little or no idea of the risks associated with its use. Patients, health care professionals, and the public should be educated about the dangers and the considerable risks of cocaine use. This review concentrates on the cardiovascular effects of cocaine and their management.

See end of article for authors' affiliations

........................

Correspondence to: Dr M Egred,

Cardiothoracic Centre,

Thomas Drive, Liverpool

L14 3PE, UK; m.egred@ ctc.nhs.uk

Submitted

9 September 2004

Accepted

28 December 2004



ocaine is the second commonest illicit drug used and the most frequent cause of drug related deaths. The younger age group of 18-25 are the most common users and it is estimated that $11 \%$ of the population has used it at some point. ${ }^{1-2}$ Cocaine may be taken by smoking, nasal inhalation, or injection with varying pharmacokinetics leading to peak blood concentration ranging from 1 to 90 minutes. Its use is associated with both acute and chronic complications that may involve any system, the most common being the cardiovascular system. ${ }^{2-4}$ Complications can also follow any route of administration. ${ }^{5}$ It is worth noting that preexistent vascular disease or other abnormalities are not a prerequisite for the development of cocaine related cardiovascular complications. ${ }^{5}$

Cocaine misuse and its related morbidity are important and have to be considered on the differential diagnosis of cardiovascular events in young adults because of its major effect and the resulting loss of productivity and undue morbidity with its related cardiac and cerebrovascular events.

Cocaine related complications include

- Cardiac: myocardial ischaemia, coronary artery spasm, acute myocardial infarction (MI), atherosclerosis, myocarditis, cardiomyopathy, arrhythmia, hypertension, and endocarditis.

- Vascular: aortic dissection and rupture, vasculitis. ${ }^{6}$

- Gastrointestinal: mesenteric ischaemia or infarction, perforation. ${ }^{7}$

- Pulmonary: pulmonary oedema, pulmonary infarction, and haemoptysis. ${ }^{8}$
- Genitourinary and obstetric: renal and testicular infarction, abruptio placentae, spontaneous abortion, prematurity, and growth retardation. ${ }^{9}$

- Neurological: seizures, migraine, cerebral infarction, and intracranial haemorrhage. ${ }^{10}$

- Musculoskeletal and dermatological: rhabdomyolysis, skin ischaemia, superficial and deep venous thrombosis, and thrombophlebitis. ${ }^{11}$

In this review we will focus on the cardiovascular effects of cocaine.

\section{PHARMACOLOGY OF COCAINE}

Cocaine (benzoylmethylecgonine, $\mathrm{C}_{17}, \mathrm{H}_{21}, \mathrm{NO}_{4}$ ) is an alkaloid extract from the leaf of the Erythroxylon coca plant, which usually grows in South America. It is available in two forms:

- Hydrochloride salt: prepared by dissolving the alkaloid in hydrochloric acid forming a water soluble powder or granule that decomposes when heated. It can be taken orally, intranasally, or intravenously.

- Free base: manufactured by processing the cocaine with ammonia or sodium bicarbonate (baking soda). It is a heat stable form that melts with temperature allowing it to be smoked and it is known as "crack" because of the popping sound it makes when heated. Crack cocaine is considered the most potent and addictive form.

Cocaine is absorbed, in both forms, from all body mucus membranes. The peak effect ranges from 1 to 90 minutes depending on the route of administration. The half life ranges from ${ }^{6} 0 \mathrm{~min}-$ utes after inhalation or intravenous injection to two to three hours after gastrointestinal ingestion, with duration of action between 15 minutes by intravenous or inhalation routes to three hours by the gastrointestainal route. (table 1).

Cocaine is metabolised to inactive water soluble metabolites (benzoylecgonine and ecgonine methyl ester) by hepatic and plasma cholinesterase and also by non-enzymatic hydrolysis. The elderly population, people with liver disease, the fetus, infants, pregnant women, and adults with pseudicholinesterase deficiency have lower cholinesterase activity and thus carry an increased risk with cocaine. The concomitant use of cocaine and alcohol, a common practice in young users, has a dangerous and multiplicative cardiovascular risk. They are metabolised in the liver to cocaethylene, which has been associated with a 40-fold increase in risk for acute cardiac events and 25 -fold increase in sudden death. ${ }^{12}$

Cocaine water soluble metabolites are excreted in the urine, ${ }^{13}$ which remains positive for cocaine 
metabolite up to 72 hours, providing an indicator of recent cocaine use. ${ }^{14}{ }^{15}$ Norcocaine is formed by an $\mathrm{N}$-demethylation reaction, and represents less than $5 \%$ of the total quantity of cocaine metabolites. It may mediate delayed effects of cocaine via enterohepatic recirculation. ${ }^{16}$ Cocaine use can also be detected by hair analysis, which is a sensitive marker and provides information about cocaine use in the preceding weeks or months, depending on the length of the hair analysed. ${ }^{9}$ Interestingly, the prevalence of cocaine use is three to five times more than in standard surveys and interview with patients, when hair analysis was used. ${ }^{17} 18$

\section{MECHANISM OF ACTION}

Cocaine acts as a powerful sympathomimetic agent. It blocks the presynaptic reuptake of norepinephrine and dopamine producing high level of these neurotransmitters at the postsynaptic receptors. ${ }^{2}$ Cocaine also may increase the release of catecholamines from central and peripheral stores. ${ }^{19}$ It can act as a local anaesthetic by blocking the initiation and transmission of electrical signals, as it inhibits membrane permeability to sodium during depolarisation. ${ }^{20}$ The arrythmogenic potential of cocaine has led to the decline in its use in ear, nose, eye, and throat surgery. ${ }^{21}$

Cocaine produces a dose dependent increase in blood pressure and heart rate, which, in recreational doses, usually remains within the physiological range. ${ }^{21}$ The sympathomimetic actions of cocaine, at cellular level, are mediated by stimulation of the $\alpha$ and $\beta$ adrenergic receptors. Cocaine also interacts with the muscarinic receptors, ${ }^{22}$ and inhibits the reuptake of dopamine and seretonin by nerve endings.

\section{CARDIOVASCULAR EFFECTS OF COCAINE USE}

The most common symptom in cocaine users is chest pain, ${ }^{4}$ and the most common cardiac disorders is ischaemia and acute coronary syndrome, which can occur with all routes of cocaine intake. ${ }^{23}$ Other cardiac problems include myocarditis, cardiomyopathy, and arrhythmias.

\section{COCAINE RELATED CHEST PAIN AND MYOCARDIAL INFARCTION}

The commonest cocaine related cardiovascular problem is chest pain with $57 \%$ of these patients admitted to the hospital. ${ }^{25}$

Myocardial infarction after cocaine use involves several mechanisms. It is related to the block of the re-uptake of norepinephrine that leads to $\alpha$ and $\beta$ adrenergic effects. These include increased heart rate and blood pressure and simultaneous coronary vasospasm with reduced oxygen delivery leading to myocardial ischaemia. ${ }^{19}$ In addition, there is evidence that cocaine activates platelets, increases platelets aggregability, and potentiates thromboxane production promoting thrombus formation. ${ }^{26-28}$

Acute coronary events and MI can occur minutes after cocaine administration or as late as few days afterwards. ${ }^{24}$ The highest risk is in the first hour after cocaine use with no relation to the dose or route of administration. ${ }^{24}{ }^{29}$ Cocaine induced MI often occurs in patients with normal coronary arteries and the typical patient is described as a man in his 30 s with only smoking as a coronary risk factor. ${ }^{29-32}$ Half of these patients would have experienced chest pain previously. ${ }^{24}$ Interestingly, the anterior wall is involved in most cases $(77 \%)$ of cocaine induced MI. ${ }^{31}$ Chest pain and ECG changes are very common in cocaine users even in the absence of myocardial ischaemia and $\mathrm{MI}^{31}$ and only $6 \%$ of cocaine induced chest pain are attributable to $\mathrm{MI}^{25}$

The risk of MI is increased up to 24 times over baseline in the first 60 minutes after cocaine use. In one series, $1 \%$ of patients who had an acute MI, had used cocaine within the previous year. Of this group, about $25 \%$ used cocaine within 60 minutes before the infarct. ${ }^{29}$

Young patients presenting with chest pain and suspected acute coronary syndrome should be questioned about cocaine use.

Cocaine induced MI can be difficult to diagnose accurately, as the ECG is difficult to interpret in young patients, with the high incidence of early repolarisation and left ventricular hypertrophy. On the other hand, MI can occur with normal ECG or with only non-specific findings. Up to $84 \%$ of patients with cocaine induced chest pain may have an abnormal ECG and up to $43 \%$ of cocaine misusers without MI may have ST segment elevation in two or more ECG leads that may even meet the thrombolysis criteria. ${ }^{25} 3233$ The reported ECG sensitivity for detecting cocaine induced MI is 36\% with a $90 \%$ specificity. ${ }^{25}$

Serum creatine kinase is not a reliable indicator of myocardial injury and is increased in almost half of cocaine users without MI. This is thought to be attributable to rhabdomyolysis. In contrast, cardiac troponins are more sensitive and specific for myocardial injury and should be used for the diagnosis of MI. ${ }^{33-36}$

Complications after cocaine induced MI, fortunately, have a low incidence, possibly because of the young age of most patients, and occur mostly within 12 hours of presentation. Ventricular arrhythmias occur in $4 \%$ to $17 \%$, congestive heart failure in $5 \%$ to $7 \%$, and death in less than $2 \%$. However, continuous cocaine use and recurrent chest pain are common, with occasional recurrent non-fatal MI or death. ${ }^{37} 38$

\section{CARDIAC ARRHYTHMIAS}

A wide range of benign and malignant arrhythmias has been reported with cocaine use. The arrhythmias are usually transient and resolves when cocaine is metabolised. Sinus tachycardia and bradycardia, supraventricular arrhythmias, bundle branch block, ventricular fibrillation or asystole, ventricular tachycardia, and torsade de pointes have all been reported. $.^{23} 39-41$

The autonomic imbalance and the changed cardiac automaticity, caused by the high adrenergic state, are thought to trigger arrhythmia. ${ }^{30} 42$ Re-enterant tachycardia may also result from the electrical inhomogeneity caused by the cocaine induced ischaemia. ${ }^{43}$ On the other hand, cocaine can lead to prolongation of the QRS and QTc duration, like class IA antiarrythmic agents, hence a deleterious combination with other agents that prolong QTC.

\section{CARDIOMYOPATHY AND MYOCARDITIS}

Dilated cardiomyopathy has been reported in cocaine users and is thought to be attributable to the direct toxic effects of

\begin{tabular}{llll} 
Table 1 & \multicolumn{3}{l}{ Pharmacokinetics of cocaine according to the route of administration } \\
\hline Route of administration & Onset of action & Peak effect & Duration of action \\
\hline Inhalation (smoking) & $3-5$ seconds & $1-3$ minutes & $5-15$ minutes \\
Intravenous & $10-60$ seconds & $3-5$ minutes & $20-60$ minutes \\
Intranasal or mucusal & $1-5$ minutes & $15-20$ minutes & $60-90$ minutes \\
Gastrointestinal & Up to 20 minutes & Up to 90 minutes & Up to 180 minutes \\
\hline
\end{tabular}


cocaine on the heart leading to heart failure because of myofibrils destruction, interstitial fibrosis, and myocardial dilatation. The cocaine induced hyperadrenergic state may also contribute to the cardiomyopathy, ${ }^{44}$ similar to that seen in pheochromocytoma.

Myocarditis was reported in $20 \%$ to $30 \%$ of patients dying from cocaine misuse, as well as on myocardial biopsies of active users. ${ }^{42} 445$ The mechanism is thought to be either secondary to hypersensitivity reactions leading to vasculitis and myocarditis, or attributable to catecholamine induced cardiac toxicity.

Fortunately, myocardial dysfunction is reversible with abstinence, so is cocaine induced myocarditis in its early stages. ${ }^{46-49}$

Heart failure and cardiomegaly in a young person should raise the possibility of cocaine misuse. ${ }^{50}$

\section{STROKE}

The risk of stroke is considerably increased with cocaine use. $^{5152}$ Cerebral ischaemia and stroke result from multiple factors, similar to myocardial ischaemia. Cocaine causes vasospasm, because of high levels of monoamines (dopamine), ${ }^{53}$ and may cause thrombus formation leading to cerebral ischaemia, ${ }^{55}$ which leads to hypoperfusion and neurological deficits. Long term cocaine use can also lead to cognitive deficits. ${ }^{56}$ Cocaine can also lead to rupture of preexisting cerebral and mycotic aneurysms.

The risk of cerebral haemorrhage is increased with continuous cocaine use, because of weakened vessel walls that result from the repeated ischaemic episodes and reperfusion. Dihydropyridine calcium channel blockers may prevent cocaine induced cerebral vasospasm. ${ }^{57}$

\section{ENDOCARDITIS}

Cocaine use seems to be a greater independent risk factor for developing endocarditis than the use of other drugs and the endocarditis associated with cocaine misuse, in contrast with endocarditis associated with other drugs, often involves the left sided cardiac valves. ${ }^{58}$ It is presumed that the increase in heart rate and blood pressure that result from cocaine use may lead to valvular and vascular injury that predisposes to bacterial invasion, as well as the immunosuppressive effects of cocaine that may increase the risk of infection. ${ }^{59}$

\section{AORTIC DISSECTION}

The use of crack cocaine can lead to acute aortic dissection. ${ }^{60}$ Dissection results probably from the increase in systemic arterial pressure caused by cocaine and should be considered as a possible cause of chest pain in cocaine users. ${ }^{61}{ }^{62}$

\section{MANAGEMENT OF COCAINE RELATED CHEST PAIN}

Recognising that ischaemia or infarction is attributable to cocaine use is critical for optimal management.

The first line treatment in patients with chest pain and ECG changes after cocaine use, according the AHA/ACC guidelines, is benzodiazepines, aspirin, and nitrates. ${ }^{36}$ Benzodaizepines reduce blood pressure and heart rate and are recommended especially in patients with associated hypertension, tachycardia, or anxiety. Aspirin prevents thrombus formation and nitrates reverse cocaine induced coronary vasoconstriction. Oxygen also should be given and would help in limiting myocardial ischaemia.

Calcium channel blockers and $\alpha$ blockers can be added as a second line treatment. ${ }^{63-65}$ Thrombolytic therapy should be used with caution and only if signs of infarction persist. ${ }^{32} 36$

The use of $\beta$ blockers can be deleterious and should be avoided in the acute stage, as their use may worsen vasospasm by permitting unopposed stimulation of $\alpha$ receptors. ${ }^{66}$ Labetalol, which has a combined $\alpha / \beta$ blocker effect, was shown to reduce the rise in blood pressure with no effect on cocaine induced coronary vasoconstriction. ${ }^{67}$

The use of thrombolytic therapy in patients with cocaine related infarction remains controversial. It should be restricted to patients who have continued evidence of evolving MI despite the administration of first line medical treatment, ${ }^{36}{ }^{68}$ and when immediate coronary angiography and angioplasty are not available, as experience with thrombolytic therapy in this clinical scenario is limited with reports of catastrophic complications associated with its use in cocaine users, ${ }^{69}{ }^{70}$ in addition to the difficulty in identifying MI by standard ECG criteria. ${ }^{33}$ Primary percutaneous coronary intervention may be a safer approach in those with definite MI, especially in the presence of cocaine use complications such as severe hypertension, seizures, intracerebral haemorrhage, or aortic dissection. ${ }^{23}$

The proarrhythmic and proconvulsant effects of antiarrhythmic drugs may be additive to that of cocaine and their use should be cautious. The use of sodium bicarbonate for cocaine induced conduction abnormalities and rhythm disturbance is being evaluated. ${ }^{25}$

The mechanism of MI and the high prevalence of chest pain without MI have important implications in management decisions. Not all patients who come to hospital with chest pain after cocaine use will need to be admitted. A recent study suggested that a 12 hour observation period with serial ECG and cardiac enzymes would be safe and reasonable to rule out acute MI and select patients who need to be admitted. ${ }^{71}$ This approach is expected to be highly cost effective. ${ }^{72}$

The incidence of late complications among patients, admitted with cocaine related chest pain, and in whom MI has been ruled out, seems low. In one study the one year survival was $98 \%$ and the incidence of late MI was around $1 \%{ }^{38}$ About two thirds of patients (60\%) admitted with cocaine associated chest pain continue to use cocaine in the year after the symptomatic episode. ${ }^{38}$

\section{CONCLUSION}

The recognition of cocaine induced ischaemia or MI is crucial for optimal management. A previously healthy young person presenting with cardiac type chest pain or MI should be asked about cocaine use. Many cocaine users have little or no idea of the risks associated with its use. Patients, health care professionals, and the public should be educated about the dangers and the considerable risks of cocaine use. People with cocaine misuse or dependence, particularly young men, should be encouraged to stop and should be referred for rehabilitation.

\section{Authors' affiliations}

M Egred, Cardiothoracic Centre, Liverpool, UK

G K Davis, University Hospital Aintree, Liverpool, UK

Funding: none.

Conflicts of interest: none.

\section{REFERENCES}

1 Department of Health and Human Services, Substance Abuse and Mental Health Services Administration. National household survey on drug abuse: main findings. Rockville, MD: Department of Health and Human Services, 2000.

2 Lange RA, Hillis LD. Cardiovascular complications of cocaine use. N Engl J Med 2001;345:351-8.

3 Substance Abuse and Mental Health Services Administration. National household survey on drug abuse: population estimates 1998. Rockville, MD: Substance Abuse and Mental Health Services Administration, 1999.

4 Brody SL, Slovis CM, Wrenn KD. Cocaine-related medical problems: consecutive series of 233 patients. Am J Med 1990;88:325-31.

5 Goldfrank LR, Hoffman RS. The cardiovascular effects of cocaine. Ann Emerg Med 1991;20:165-75. 
6 Krendel DA, Ditter SM, Frankel MR, et al. Biopsy-proven cerebral vasculitis associated with cocaine abuse. Neurology 1990;40:1092-4.

7 Niazi $M$, Kondru A, Levy J, et al. Spectrum of ischemic colitis in cocaine users. Dig Dis Sci 1997:42:1537-41

8 Haim DY, Lippmann ML, Goldberg SK, et al. The pulmonary complications of crack cocaine. A comprehensive review. Chest 1995; 107:233-40.

9 Ness RB, Grisso JA, Hirschinger N, et al. Cocaine and tobacco and the risk of spontaneous abortion. N Engl J Med 1999;340:333-9.

10 Daras $M$, Tuchman AJ, Marks S. Central nervous system infarction related to cocaine abuse. Stroke 1991:22:1320-5.

11 Roth D, Alarcon FJ, Fernandez AJ, et al. Acute rhabdomyolysis associated with cocaine intoxication. N Engl'J Med 1988;319:673-7.

12 Keegan A. Cocaine plus alcohol, a deadly mix. NIDA Notes 1991;6:18.

13 Jeffcoat AR, Perez-Reyes M, Hill JM, et al. Cocaine disposition in humans after intravenous injection, nasal insufflation (snorting), or smoking. Drug Metab Dispos 1989;17:153-9.

14 Das G. Cardiovascular effects of cocaine abuse. Int $J$ Clin Pharmacol Ther Toxicol 1993;31:521-8.

15 Om A, Ellahham S, DiSciascio G. Management of cocaine induced cardiovascular complications. Am Heart J 1993;125:469-75.

16 Inaba T, Stewart DJ, Kalow W. Metabolism of cocaine in man. Clin Pharmacol Ther 1978;23:547-52.

17 Kidwell DA, Blanco MA, Smith FP. Cocaine detection in a university population by hair analysis and skin swab testing. Forensic Sci Int 1997:84:75-86

18 Fendrich M, Johnson TP, Sudman S, et al. Validity of drug use reporting in a high-risk community sample: a comparison of cocaine and heroin survey reports with hair tests. Am J Epidemiol 1999; 149:955-62.

19 Gradman AH. Cardiac effects of cocaine: a review. Yale J Biol Med 1988;61:137-47.

20 Mouhaffel AH, Madu EC, Satmary WA, et al. Cardiovascular complications of cocaine. Chest 1995; 107:1426-34.

21 Orr D, Jones I. Anesthesia for laryngoscopy: a comparison of the cardiovascular effects of cocaine and lignocaine. Anesthesia 1968;23:194-202.

22 Xiao YF, Morgan JP. Cocaine blockade of the acetylcholine-activated muscarinic $\mathrm{K}+$ channel in ferret cardiac myocytes. J Pharmacol Exp Ther 1998;284:10-18

23 Isner JM, Estes NA, Thompson PD, et al. Acute cardiac events temporally related to cocaine abuse. N Engl J Med 1986;315:1438-43.

24 Hollander JE, Hoffman RS. Cocaine-induced myocardial infarction: an analysis and review of the literature. J Emerg Med 1992;10:169-77.

25 Hollander JE, Hoffman RS, Gennis P, et al. Prospective multicenter evaluation of cocaine-associated chest pain. Cocaine Associated Chest Pain (COCHPA) Study Group. Acad Emerg Med 1994;1:330-9.

26 Tonga G, Tempesta E, Tonga AR, et al. Platelet responsiveness and biosynthesis of thromboxane and prostacyclin in response to in vitro cocaine treatment. Haemostasis 1985;15:100-7.

27 Kugelmass AD, Shannon RP, Yeo EL, et al. Intravenous cocaine induces platelets activation in the conscious dog. Circulation 1995;91:1336-40

28 Heesch CM, Withelm CR, Ristich J, et al. Cocaine activates platelets and increases the formation of circulating platelet containing microaggregates in humans. Heart 2000:83:688-95.

29 Mittleman MA, Mintzer D, Maclure M, et al. Triggering of myocardial infarction by cocaine. Circulation 1999;99:2737-41

30 Lange RA, Willard JE. The cardiovascular effects of cocaine. Heart Dis Stroke 1993:2:136-41.

31 Minor RL Jr, Scott BD, Brown DD, et al. Cocaine-induced myocardial infarction in patients with normal coronary arteries. Ann Intern Med 1992;115:797-806

32 Hollander JE. The management of cocaine-associated myocardial ischemia. N Engl J Med 1995:333:1267-72.

33 Gitter MJ, Goldsmith SR, Dunbar DN, et al. Cocaine and chest pain: clinical features and outcome of patients hospitalised to rule out myocardial infarction. Ann Intern Med 1991; 1 15:277-82.

34 Hollander JE, Levitt MA, Young GP, et al. Effect of recent cocaine use on the specificity of cardiac markers for diagnosis of acute myocardial infarction. Am Heart J 1998; 135:245-52

35 Mclaurin M, Apple FS, Henry TD, et al. Cardiac troponin I and T concentrations in patients with cocaine-associated chest pain. Ann Clin Biochem 1996:33:183-6.

36 Braunwald E, Antman E, Beasley J, et al. ACC/AHA 2002 guideline update for the management of patients with unstable angina and non-ST-segmen elevation infatcrion-summary article. A report of the American College of Cardiology/American Heart Association task force on practice guidelines (Committee on the Management of Patients With Unstable Angina). J Am Coll Cardiol 2002;40:1366-74

37 Hollander JE, Hoffman RS, Burstein JL, et al. Cocaine-associated myocardial infarction: mortality and complications. Arch Intern Med 1995:155:1081-6.

38 Hollander JE, Hoffman RS, Gennis P, et al. Cocaine-associated chest pain: one-year follow-up. Acad Emerg Med 1995;2:179-84.
39 Bauman JL, Grawe JJ, Winecoff AP, et al. Cocaine-related sudden cardiac death: a hypothesis correlating basic science and clinical observations. J Clin Pharmacol 1994;34:902-11.

40 Om A, Ellenbogen KA, Vetrovec GW. Cocaine-induced bradyarrhythmias. Am Heart J 1992:124:232-4.

41 Nanii AA, Filipenko JD. Asystole and ventricular fibrillation associated with cocaine intoxication. Chest 1984;85:132-3.

42 Kloner RA, Hale S, Alker K, et al. The effects of acute and chronic cocaine use of the heart. Circulation 1992;85:407-19.

43 Billman GE, Lappi MD. Effects of cocaine on cardiac vagal tone before and during coronary artery occlusion: cocaine exacerbates the autonomic response to myocardial ischemia. J Cardiovasc Pharmacol 1993;22:869-76.

44 Virmani R, Robinowitz M, Smialek JE, et al. Cardiovascular effects of cocaine: an autopsy study of 40 patients. Am J Med 1986;81:699-701.

45 Peng SK, French WJ, Pelikan PC. Direct cocaine cardiotoxicity demonstrated by endomyocardial biopsy. Arch Pathol Lab Med 1989;113:842-5.

46 Isner JM, Chokshi SK. Cardiovascular complications of cocaine. Curr Probl Cardiol 1991;16:89-123.

47 Henzlova MJ, Smith SH, Prchal VM, et al. Apparent reversibility of cocaineinduced congestive cardiomyopathy. Am Heart J 1991;122:577-9.

$48 \mathrm{Om} \mathrm{A}$, Ellahham S, Ornato JP. Reversibility of cocaine-induced cardiomyopathy. Am Heart J 1992;124:1639-41.

49 Chokshi SK, Moore R, Pandian NG, et al. Reversible cardiomyopathy associated with cocaine intoxication. Ann Intern Med 1989:111:1039-40.

50 Willens HJ, Chakko SC, Kessler KM. Cardiovascular manifestations of cocaine abuse. A case of recurrent dilated cardiomyopathy. Chest 1994; 106:594-600

51 Petitti DB, Sidney S, Quesenberry C, et al. Stroke associated with cocaine or amphetamine use. Epidemiology 1998:9:596-600.

52 Klonoff DC, Andrews BT, Obana WG. Stroke associated with cocaine use. Arch Neurol 1989;46:989-93.

53 Kaufman MJ, Levin JM, Maas LC, et al. Cocaine decrease relative cerebral blood volume in humans: a dynamic susceptibility contrast magnetic resonance imaging study. Psychopharmacology (Berl) 1998;138:76-81.

54 Johnson B, Lamki L, Fang B, et al. Demonstration of dose-dependent global and regional cocaine-induced reductions in brain blood flow using a novel approach to quantitative single photon emission comuterised tomography. Neuropsychopharmacology 1998;18:37784.

55 KonzennJP, Levine SR, Garcia JH. Vasospasm and thrombus formation as possible mechanisms of stroke related to alkaloid cocaine. Stroke 1995;26:1114-18.

56 Robinson JE, Heaton RK, O'Malley SS. Neuropsychological functioning in cocaine abusers with and without alcohol dependence. $J$ Int Neuropsychol Soc 1999:5:10-19.

57 Johnson BA, Devous MD Sr, Ruiz P, et al. Treatment advances for cocaineinduced ischemic stroke: focus on dihydropyridine-class calcium channel antagonists. Am J Psychiatry 2001;158:1191-8.

58 Chambers HF, Morris DL, Tauber MG, et al. Cocaine use and the risk for endocarditis in intravenous drug users. Ann Intern Med 1987;106:833-6.

59 Mao JT, Zhu LX, Sharma S, et al. Cocaine inhibits human endothelial cell IL-8 production: the role of transforming growth factor-beta. Cell Immunol 1997:181:38-43.

60 Hsue PY, Salinas CL, Bolger AF, et al. Acute aortic dissection related to crack cocaine. Circulation 2002; 105:1592-5.

61 Madu EC, Shala B, Baugh D. Crack-cocaine-associated aortic dissection in early pregnancy- a case report. Angiology 1999;50:163-8.

62 Baumgartner FJ, Omari BO. Method of repair of cocaine-induced chronic type A aortic dissection. Ann Thorac Surg 1997;64:1518-19.

63 Lange RA, Cigarroa RG, Flores ED, et al. Cocaine-induced coronary artery vasoconstriction. N Engl J Med 1989;321:1557-62.

64 Hollander JE, Carter WA, Hoffman RS. Use of phentolamine for cocaineinduced myocardial ischemia. N Engl J Med 1992;327:361

65 Negus BH, Willard JE, Hillis LD, et al. Alleviation of cocaine-induced coronary vasoconstriction with intravenous verapamil. Am J Cardiol 1994;73:510-13.

66 Lange RA, Cigarroa RG, Flores ED, et al. Potentiation of cocaine-induced coronary vasoconstriction by beta-blockade. Ann Intern Med 1990;112:897-903

67 Boehrer JD, Moliterno DJ, Willard JE, et al. Influence of labetalol on cocaineinduced coronary vasoconstriction in humans. Am J Med 1993;94:608-10.

68 Anonymous. Guidelines 2000 for cardiopulmonary resuscitation and emergency cardiovascular care. Part 8: advanced challenge in resuscitation: section 2, toxicology in ECG. Circulation 2000;102(suppl 8):1223-8.

69 Hoffman RS, Hollander JE. Thrombolytic therapy and cocaine-induced myocardial infarction. Am J Emerg 1996;14:693-5.

70 Hollander JE, Burstein JL, Hoffman RS, et al. Cocaine-associated myocardial infarction: clinical safety of thrombolytic therapy. Chest 1995:107:1237-41.

71 Weber JE, Shofer FS, Larkin GL, et al. Validation of brief observation period for patients with cocaine associated chest pain. N Engl J Med 2003;348:510-17.

72 Kloner RA, Rezkalla SH. Cocaine and the heart. N Engl J Med 2003:348:487-4. 